УДК $82.091+821.131 .1$

DOI: $10.17223 / 24099554 / 10 / 9$

\title{
Элизабетта Монделло
}

\section{РОССИЯ В ПУТЕВЫХ ЗАПИСКАХ ИТАЛО КАЛЬВИНО И АЛЬБЕРТО МОРАВИА}

\begin{abstract}
Описывается культурно-политический и литературный контекст очерков Итало Кальвино "Дневник путешествия в Советский Союз» и Альберто Моравиа «Месяч в СССР», первоначально опубликованных соответственно в 1953 и 1956 г2. в итальянских газетах. Выявляется своеобразие авторских стратегий в подаче материала, определенное различием возраста, статуса и мировоззренческих ориентаций двух писателей.

Ключевые слова: СССР, Россия, итальянская литература, путевые записки, Итало Кальвино, "Дневник путешествия в Советский Союз», Альберто Моравиа, «Месяи в СССР».
\end{abstract}

Какое странное, и манящее, и несущее, и чудесное в слове: дорога! и как чудна она сама, эта дорога!

Н.В. Гоголь

Статья посвящена путешествиям по России двух крупнейших итальянских писателей второй половины XIX в., Итало Кальвино и Альберто Моравиа, которые в 1950-х гг. имели возможность провести несколько недель в Советском Союзе, пережив сложные, интригующие и эмоционально насыщенные впечатления, отраженные ими в обширных репортажах; оба проявили себя как любознательные путешественники и изощренные нарраторы, не особенно склонные к обычным туристическим банальностям. Очерки Кальвино и Моравиа, публиковавшиеся в периодических изданиях тех лет и после собранные под названиями «Дневник путешествия в Советский Союз» ${ }^{1}$

\footnotetext{
${ }^{1}$ Путевые заметки Кальвино (от октября 1951 г.) публиковались в «Унита́» в феврале-марте 1953 г.; позже они были собраны в книге очерков Кальвино в разделе «Описания и репортажи» под названием «Дневник путешествия в Советский Союз» [1]. В издании Мондадори, включающем 22 текста «Дневника»,
} 
и «Месяц в СССР $»^{2}$ соответственно, предлагают современному читателю много больше, нежели просто любопытные примеры литературы путешествий: рисуя публике картину России первых лет после окончания Второй мировой войны, они в первую очередь демонстрируют точку зрения, мировоззрение и мнения воинствующих в своей социальной ориентированности интеллектуалов по отношению к тому миру, с которым их связывает чувство солидарности и симпатии. Кальвино и Моравиа описывают очень разные топосы; их персонажи также очень различны (это, например, студентка филологического факультета МГУ и узбекский колхозник), но оба писателя сосредоточены главным образом на своих переживаниях, убеждениях и утопических представлениях; от этого их повествование приобретает эгоцентричный и авторефлексивный характер. Пытаясь найти для себя сущность России, они находят самих себя - сообразно с типичной и коварной способностью травелога незаметно выдвигать в центр повествования и делать его объектом его субьект: «Путешествие - это путешественник», - как утверждает в лапидарной формуле Фернандо Пессоа в своей «Книге тревог», прибавляя затем: «То, что мы видим - не то, что мы видим, но то, что мы суть» [5. Р. 98].

В целом можно говорить о двух характеризующихся общими стилевыми и функциональными особенностями циклах статей, печатавшихся как репортажи в периодических изданиях, с которыми оба писателя постоянно сотрудничали. Однако их политические убеждения и их роль в итальянской словесной культуре глубоко различны: статьи Кальвино появлялись в газете «Унита́», органе Коммунистической партии Италии, а Моравиа писал для «Коррьере делла сера», миланского ежедневного издания с большой историей, традиционно ориентрованного на ломбардскую буржуазию и мир предпринимателей. Оба автора были политически ангажированы. Кальвино был

учтены и рукописные материалы, сохранившиеся в архиве Кальвино. Некоторые из этих очерков не опубликованы ни в одном из изданий «Унита́» (Рим, Турин, Милан и Генуя); в изданных текстах имеются разночтения, в том числе и в названиях очерков [2].

${ }^{2}$ Корреспонденции Моравиа (относящиеся к 1956 г.) публиковались начиная с 15 августа 1956 г. в «Корриере дела Сера» (первой публикацией был очерк «Мавзолей Ленина и Сталина»). В один том были собраны и изданы два года спустя [3] (Переизд. [4]). Издание включает также литературно-критической очерк «L'antieroe nel romanzo russo», впервые опубликованный 14 сентября 1954 г. 
членом партии; он предпринял поездку в Россию в качестве члена официальной делегации должностных лиц по приглашению Федерации коммунистической молодежи Италии и, как кажется, в своих репортажах старался ясно и пунктуально отдать отчет читателям газеты в том, что он увидел за дни, проведенные им в Москве, Ленинграде и Баку. Позиция Моравиа тоже определяется официальностью его приглашения в Россию со стороны советских органов власти: он был членом делегации, в которой числились другие склонные к марксизму и близкие к левым представители итальянской интеллектуальной элиты, такие как археолог и историк искусства Ранунчо Бьянки Бандинелли и журналист Сандро Де Фео [6. Р. XXXV]. Стиль очерков Моравиа публицистичен - это стиль зарубежного посланца или наблюдателя местных нравов с остраненной и сугубо индивидуальной точки зрения: его путевой дневник необычен уже тем, что уводит читателя в Грузию, Среднюю Азию и Узбекистан. Кроме Москвы и Ленинграда Моравиа посетил Тбилиси, Ереван, Ташкент и Самарканд.

Записки Кальвино и Моравиа о путешествиях по Советскому Союзу ценны не столько тем, что в них зафиксирован нетипичный опыт транснационального контакта, сколько тем, что они принадлежат выдающимся фигурам общей панорамы культурной и литературной жизни Италии во второй половине XIX в. Напротив, в итальянской литературе путешествий второй половины XIX в. так много русских травелогов, что они заслуживают быть выделенными в особую группу в пределах более обширной категории литературы путешествий наравне с двумя другими ее мощными пластами: путевыми записками о Юго-Восточной Азии и об Америке. Страсть к таинственному Востоку объединила все европейские литературы и всех европейских интеллектуалов, очарованных Востоком и прежде всего Индией, которая стала своего рода вожделенным пределом стремлений целого поколения прозаиков и поэтов, создавших ее словесные образы [7. Р. 815] и мечтающих обрести в ней «иную» духовность, лучшую, нежели западная. Одновременно с этим стремлением на Восток многие художники и писатели стали завязывать отношения с Соединенными Штатами и обживать Америку, надеясь увидеть современность, иную, чем европейская, и на собственном опыте почувствовать динамику заокеанской жизни. Для всего XIX в. Америка - это канонический символ инноваций и прогресса, фантастический Новый Мир, особенно интенсивно мифологизировавший- 
ся в Италии в 1930-е гг. из-за ограничений свободы, принесенных фашистским режимом: тот же Моравиа, враждовавший с фашизмом, в декабре 1935 г. предпринял отважное, если не сказать авантюрное, путешествие в Соединенные Штаты, погрузившись на трансатлантический лайнер «Рекс» с билетом туристического класса, но без единого сольдо в кармане. В Нью-Йорке он добывал себе пропитание лекциями по истории итальянского романа при поддержке писателя Джузеппе Преццолини, который предоставил ему место руководителя «Итальянского дома» при Колумбийском университете [7. Р. 812].

Если теперь вернуться к России, можно сказать, что образ страны, сложившийся в Италии между двумя войнами, представлял собой картину незнакомой планеты, необъятного пространства с беспрецедентной социоэкономической системой, который одновременно притягивал и отталкивал многих итальянских интеллектуалов, испытывавших настоятельное желание увидеть собственными глазами страну, в которой, по словам Андре Жида, «утопия действительно стала реальностью» [8. Р. 51] $]^{3}$. Если мы бегло просмотрим биографии хотя бы двадцати самых известных писателей этой эпохи, мы убедимся, насколько путешествие в СССР - иногда это высказывалось даже открытым текстом - обладало для них ярко выраженной культурно-политической мотивацией; это стремление породило множество действительно выдающихся свидетельств: дневников, отчетов, репортажей (многие писатели были сотрудниками газет, журналов или «третьих страниц» самых престижных изданий), в которых зафиксированы самые разные, часто даже противоположные, точки зрения, неопределенность позиций которых питалась двойственным отношением к советскому режиму ${ }^{4}$. Если обратиться только к нескольким самым значительным именам литераторовпутешественников 1920-1930-х гг., то взгляд на Россию поэта Винченцо Кардарелли окажется недоброжелательным, прозаика и журналиста Курцио Малапарте - курьезным, но позитивным, романиста Коррадо Альваро - восхищенным; к этим именам можно добавить

\footnotetext{
${ }^{3}$ В цитированной работе Жид заметил: «Кто сможет когда-нибудь сказать, что значит для нас СССР? Больше, чем родина выборов, больше, чем пример и руководство. Там было осуществлено то, о чем мы мечтали, то, на что едва смели надеяться, но к чему стремились наши желания и усилия» [Там же. Р. 51].

${ }^{4}$ См. о политической картине России XX в. в путевыХ записках итальянских писателей: [9].
} 
много других, не столь известных ${ }^{5}$ в том числе имя журналиста Луиджи Бардзини: его репортажи с русских фронтов Гражданской войны вошли в историю итальянской журналистики.

Конечно же, в истории итальянско-русского травелога перевернула страницу Вторая мировая война: после 1945 г. и вплоть до конца 1970-х гг., но прежде всего в первые десятилетия после окончания Второй мировой войны, путешествие в Россию для многих итальянских интеллектуалов превратилось во что-то подобное политическому паломничеству: они отправлялись в большие русские города Москву, Ленинград, Сталинград, ехали в составе официальных делегаций, по приглашению правительственных учреждений или Союза советских писателей, чтобы сравнить русскую реальность с ее образом, существующим в их сознании, и познакомиться с русскими писателями и поэтами. Тексты, порожденные этими путешествиями, стали чем-то вроде жанровой разновидности канонического травелога и нашли свое естественное место на страницах партийного органа, газеты «Унита́»; но именно из-за своего не только политического, но и культурно-информативного содержания эти очерковые свидетельства и репортажи были востребованы и большой национальной периодикой, газетами «Стампа» и «Коррьере делла сера», где они с начала XIX в. печатались на так называемой «третьей странице» (так в Италии называется страница, посвященная новостям культуры). Так для самых разных слоев публики возникла возможность знакомиться с путевыми записками самых знаменитых итальянских писателей. Признавая заслуги «левой» печати, между 1951 и 1966 гг. буржуазно ориентированные газеты опубликовали на своих страницах, а издательства подготовили сборники корреспонденций не только Итало Кальвино и Альберто Моравиа, но и очерки Энрико Эмануэлли, Сибиллы Алерамо, Карло Леви, Анны Марии Ортезе, Пьера Паоло Пазолини, Ренаты Вигано́, Либеро Биджарелли, Пьерантонио Куарантотти Гамбини, Марио Солдати 6 . В последующие годы были изданы исследования о путевых записках многих других писателей: Марио Праца о Джанни Родари, Луиджи Малерба об Эдоардо Сангвинетти, Г. Монтесано о Джине Лагорио.

\footnotetext{
${ }^{5}$ См.: [10]. В антологии Николаи собрано более сотни текстов путевых заметок писателей, посетивших Советский Союз в период с 1929 по 1990 г. См. также: [11]. ${ }^{6}$ В антологии Николаи в разделе «1950-1960» собраны тексты 27 писателей.
} 
На фоне такой разнообразной и сложной панорамы русскоитальянского травелога довольно сложно определить, хотя бы в первом приближении, специфические черты травелогов Кальвино и Моравиа. Не имея возможности подробно проанализировать их поэтику и идеологию, ограничусь указанием на наиболее существенные особенности их текстов; последующая работа углубит этот анализ.

Тексты Кальвино и Моравиа обнаруживают некоторые общие черты и большое своеобразие; это последнее объясняется прежде всего тем, что путешествия, которые они предприняли в 1951 и 1956 гг. соответственно, разделены довольно продолжительной временной дистанцией: это две совершенно разных эпохи такого проблемного десятилетия, каким для России явились 1950-е гг. Да и возраст путешественников был очень разным: если Кальвино был совсем молодым, даже не тридцатилетним писателем с единственным имевшим успех романом «Тропа паучьих гнезд» в своем активе, то Моравиа приехал в Россию пятидесятилетним общепризнанным мэтром, знаменитым интеллектуалом, лауреатом многих литературных премий.

В 1951 г. Итало Кальвино, отправившийся в путешествие по России, был совсем молодым (рожденный в 1823 г., он 15 октября, как раз во время поездки в Россию, отметил свой 28-й день рождения) и переживал тот период, когда стабильность переплетается с изменениями: он недавно покинул Лигурию, где во время войны был партизаном, и поселился в Турине, деля свое время между работой в издательской фирме Эйнауди, Партии коммунистов Италии и партийными газетами; в 1944 г. он принимал участие во Всемирном фестивале молодежи и студентов в Праге. Ко времени поездки в СССР он уже опубликовал пользовавшиеся успехом рассказы и свой первый роман «Тропа паучьих гнезд» (1947). Летом 1951 г. он закончил социальный реалистический роман «Юноши с берегов По», в котором, однако, угадывается перспектива отхода от этого направления; летом он написал роман «Раздвоенный виконт», первый из трех романов цикла «Наши предки», принесшего ему славу.

В сентябре 1951 г. Кальвино получил от Федерации коммунистической молодежи Италии предложение войти в состав делегации, направляемой в СССР; этим приглашением он был возбужден и очень счастлив. Путешествие стало своего рода доказательством его роли в итальянской культуре - роли, незаметной за его работой 
в партийной организации и газете «Унита́», и возможностью найти реальное подтверждение тому, во что он верил, в стране, эту веру воплотившей в своей реальности. На первой странице своей «Записной книжки» Кальвино замечает, не без автобиографического подтекста: «Меня интересует возможность увидеть возмужалый социализм, социализм, которому исполнилось уже 35 лет» [1. Р. 2409]. Без сомнения, это та самая точка зрения, которая просвечивает в его корреспонденциях от октября-ноября 1951 г., опубликованных в феврале следующего года. Кальвино с энтузиазмом воспринимает все, что он видит, переходя от самого сильного впечатления (Красная площадь и мавзолей Ленина) к восторгам по поводу приема, оказываемого ему девушками, рабочими и писателями, с которыми он знакомится. Ему все нравится в устройстве советского общества, которое он постоянно сравнивает в итальянским (особенно идея «равенства», которая которая пронизывает, по его мнению, русскую жизнь и которая заслуживает пристального наблюдения). И все его поражает; как кажется, Кальвино не испытал ни изумления западных путешественников, ни их замешательства перед чуждыми реалиями русской жизни: пожалуй, это следствие того положительного предубеждения, которое находит себе подтверждение там, где хочет. «Кальвино бросился в эту поездку как в ритуал светской инициациии, - пишет Доменико Скарпа, - в ней он, сомневающийся молодой интеллектуал, сжег на алтаре социализма шлак своей нерешительности и облекся в рясу того, что Витторини в "Политехническом институте” назвал “стыдом за то, что ты буржуа”» [12. Р. 22].

Напротив, Альберто Моравиа в 1956 г., когда он отправился в СССР, был уже знаменитым писателем и литературным критиком марксистской ориентации; его литературный дебют состоялся в 1929 г. Он был лауреатом многих престижных литературных премий (таких как, например, «Стрега»), автором драматических произведений и киносценариев, основателем журнала «Нуови аргоменти»; к середине 1950-х гг. он уже пользовался всемирной славой, возрастающей после того, как в 1952 г. католическая церковь внесла его произведения в свой Индекс. Годом позже он был назван в печати «самым переводимым в Советском Союзе писателем» [13] (републикация - [14. Р. 182-184]). О своем пребывании в России Моравиа написал рассказ, собрав его из отдельных текстов, позже ставших главами книги и характеризующихся типично дневниковым нарративом, среди ко- 
торых выделяются литературно-критические фрагменты (например, «Антигерой в русской литературе»). В своем нарративе Моравиа придерживается нейтрального стиля повествователя, желающего объективно передать свои впечатления и наблюдения, избегая всяческой эмоциональности и установки на сопереживание читателя. В отличие от Кальвино Моравиа не стремится предложить читателю последовательно хронологически выдержанный дневник своего путешествия; скорее, его целью является создание картины русского мира, подчас весьма критичной. Он не пытается найти подтверждение или опровержение своим идеологическим убеждениям, несмотря на то, что 1956 г. в истории России был особенным, и сам Моравиа два десятилетия спустя признался: «Я написал книгу о Советском Союзе потому, что меня заинтересовали оттепель, сталинизм, переход от одной социальной структуры к другой» [15. Р. 1802]. Его образ России - это образ страны, которая восхищает путешественника своей природой и прекрасными пейзажами, и еще более - своей классической культурой: Достоевский, Чехов, Тургенев, Мусоргский, Есенин, Маяковский. Его путешествие было определенным образом мотивировано: Моравиа много раз возвращался в СССР, доехав до Новосибирска, Ташкента и Иркутска, но это было обусловлено тем, что в последующие годы он стал хроническим путешественником, выбирающим все более отдаленные пределы, которые связались в определенного рода цепочку: наряду с Россией ее звеньями стали Китай, Индия, Монголия, Йемен и любимая им Африка. Кальвино тоже неоднократно путешествовал - его наиболее значительной поездкой стало путешествие в США, где он провел шесть месяцев.

Подводя итог этим наблюдениям, прибавлю только, что в текстах Кальвино и Моравиа читатель, кроме всех их отмеченных выше особенностей, отчетливо видит и то, насколько неповторимым и чарующим для обоих писателей было путешествие в Россию: таковы все путешествия, и прав был Гоголь, увидевший в слове «дорога» мощный импульс чего-то «странного, и манящего, и несущего, и чудесного»!

Перевод с итальянского О.Б. Лебедевой (Томский государственный университет)

\section{Лuтература}

1. Calvino I. Taccuino di viaggio nell'Unione Sovietica // Calvino I. Saggi 1945-1985 / A c. di Mario Barenghi. Milano : Mondadori, 1995. T. 2. P. 2407-2496. 
2. Note e notizie sui testi // Calvino I. Saggi 1945-1985. / A c. di Mario Barenghi. Milano : Mondadori, 1995. T. 2. P. 3019-3025.

3. Moravia A. Un mese in URSS. Milano : Bompiani, 1958. $156 \mathrm{p}$.

4. Moravia A. Un mese in URSS / A c. di Luca Clerici. Milano : Bompiani, 2013. 189 p.

5. Pessoa F. Il libro dell'inquietudine. Milano: Feltrinelli, 1996. 288 p.

6. Clerici L. Notizia sul testo // Moravia A. Un mese in URSS. Milano : Bompiani, 2013. P. XXXV-XXXVIII.

7. De Luca B., Scarpa D. Gli scrittori in viaggio, in Atlante della letteratura italiana / A c. di Sergio Luzzatto e Gabriele Pedullà. Torino : Einaudi, 2012. Vol. 3: Dal romanticismo a oggi / A c. di Domenico Scarpa. 1057 p.

8. Gide A. Ritorno dall'URSS (1950). Roma : Edizioni Samonà e Savelli, 1969. 152 p.

9. Farsetti A. La Russia sovietica con gli occhi dei viaggiatori fascisti: frattura come (parziale) integrazione // Russia. Oriente slavo e Occidente europeo. Fratture e integrazioni nella storia e nella civiltà letteraria / A c. di Claudia Pieralli, Claire Delaunay, Eugène Priadko. Firenze : Firenze University Press, 2017. P. 133-150.

10. Nicolai G.M. Sovietlandia. Viaggiatori italiani nell'Unione Sovietica. Roma : Bulzoni, 2009. 458 p.

11. Clerici L. Introduzione // Moravia Alberto. Un mese in URSS. Milano : Bompiani, 2013. P. V-XIII.

12. Scarpa D. Come Calvino viaggiò in Urss senza vedere Stalin // Linea d'ombra. 1990. № 52. P. 20-23.

13. "Gli Indifferenti" romanzo poco casto pubblicato solo ora in Unione Sovietica // La voce repubblicana. 1976. 21 luglio. P. 3.

14. Benussi C. Il punto su Moravia. Bari : Laterza, 1987. 200 p.

15. Moravia A. Viaggi. Articoli 1930-1990 / A. c. di Enzo Siciliano. Milano : Bompiani, 1994. $1836 \mathrm{p}$.

\section{RUSSIA IN ITALO CALVINO'S AND ALBERTO MORAVIA'S TRAVEL NOTES}

Imagologiya i komparativistika - Imagology and Comparative Studies, 2018, 10, pp. 172-182. DOI: 10.17223/24099554/10/9

Elisabetta Mondello, University of Rome La Sapienza (Rome, Italia). E-mail: elisabetta.mondello@uniroma1.it

Keywords: USSR, Russia, Italian literature, travel notes, Italo Calvino, Diary of a Journey to the USSR, Alberto Moravia, Month in the USSR.

The paper describes the context of Italo Calvino's "The Diary of a Journey to the Soviet Union" and Alberto Moravia's "A Month in the USSR", originally published, respectively, in 1953 and 1956 in the Italian newspapers L'Unitá and Corriere della Sera. For Italian intellectuals, a journey to the USSR had a pronounced cultural and political motivation, and was fueled by the desire to see with their own eyes a country in which, according to Andre Gide, "utopia was becoming reality". Representatives of the Italian cultural elite went to large Russian cities - Moscow, Leningrad, Stalingrad, travelled as part of official delegations, at the invitation of government agencies or the Union of Soviet Writers. They wanted to compare Russian reality with its image 
existing in their minds, and to meet Russian writers and poets. Texts written during these journeys became a genre variety of the canonical travelogue, and found their natural place on the pages of the Italian Communist Party's official newspaper L'Unitá. However, their content was not only political, but also cultural, these testimonies and reports were also of interest for large national periodicals La Stampa and Corriere della Sera.

The texts of Calvino and Moravia reveal some common features, but also their great uniqueness; The latter is explained primarily by the fact that they made their journeys in 1951 and 1956, respectively, so the journeys were separated by the death of Stalin and the beginning of the Thaw. The travellers were of different age: Calvino was a young twenty-eight-year-old author of only one successful novel The Path to the Nest of Spiders, while Moravia came to Russia as a fifty-year-old well-known intellectual and a laureate of many literary awards.

As a result, Calvino's travelogue became a kind of evidence of his role in Italian culture, and an opportunity to find a real proof for what he believed in in the country that made this faith reality. Unlike Calvino, Moravia does not seek to offer the reader a consistently chronologically sustained diary of his journey; rather, his goal is to create a picture of the Russian world, sometimes very critical. In his narrative, Moravia adheres to the neutral style of the narrator, who wants to objectively fix his impressions and observations, avoids emotionality, and does not strive to evoke empathy in the reader.

\section{References}

1. Calvino, I. (1995) Saggi 1945-1985 [Essays of 1945-1985]. Vol 2. Milan: Mondadori. pp. 2407-2496.

2. Calvino, I. (1995) Saggi 1945-1985 [Essays of 1945-1985]. Vol 2. Milan: Mondadori. pp. 3019-3025.

3. Moravia, A. (1958) Un mese in URSS [A Month in the USSR]. Milan: Bompiani.

4. Moravia, A. (2013) Un mese in URSS [A Month in the USSR]. Milan: Bompiani.

5. Pessoa, F. (1996) Il libro dell'inquietudine [The Book of Unrest]. Milan: Feltrinelli.

6. Clerici, L. (2013) Notizia sul testo [News on the text]. In: Moravia, A. Un mese in URSS [A Month in the USSR]. Milan: Bompiani. pp. XXXV-XXXVIII.

7. De Luca, B. \& Scarpa, D. (2012) Gli scrittori in viaggio, in Atlante della letteratura italiana [The Travelling Writers, in the Atlas of Italian Literature]. Vol. 3. Torino: Einaudi.

8. Gide, A. (1969) Ritorno dall'URSS (1950) [A Return from the USSR (1950)]. Rome: Edizioni Samonà e Savelli.

9. Farsetti, A. (2017) La Russia sovietica con gli occhi dei viaggiatori fascisti: frattura come (parziale) integrazione [Soviet Russia with the eyes of fascist travelers: fracture as (partial) integration]. In: Pieralli, C., Delaunay, C. \& Priadko, E. (eds) Russia. Oriente slavo e Occidente europeo. Fratture e integrazioni nella storia e nella civiltà letteraria [Russia. Slavic East and European West. Fractures and Integration in History and Literary Civilization]. Florence: Florence University Press. pp. 133-150.

10. Nicolai, G.M. (2009) Sovietlandia. Viaggiatori italiani nell'Unione Sovietica [Sovietland. Italian travelers in the Soviet Union]. Rome: Bulzoni. 
11. Clerici, L. (2013) Introduzione [Introduction]. In: In: Moravia, A. Un mese in URSS [A Month in the USSR]. Milan: Bompiani. pp. V-XIII.

12. Scarpa, D. (1990) Come Calvino viaggiò in Urss senza vedere Stalin [How Calvino traveled to the USSR without seeing Stalin]. Linea d'ombra. 52. pp. 20-23.

13. La voce repubblicana. (1976) "Gli Indifferenti" romanzo poco casto pubblicato solo ora in Unione Sovietica ["The Indifferent", a little chaste novel published only now in the Soviet Union]. 21 July. pp. 3.

14. Benussi, C. (1987) Il punto su Moravia [The point on Moravia]. Bari: Laterza.

15. Moravia, A. (1994) Viaggi. Articoli 1930-1990 [Travels. Articles of 1930-1990]. 